\title{
The value of phenol red and chromic chloride as nonabsorbable gastric indicators
}

\author{
R. J. CLARKE AND J. ALEXANDER WILliaMS
}

From the General Hospital, Birmingham

SUMMARY A comparison is made of gastric loss of phenol red and chromic chloride other than by emptying. Chromic chloride appears to be lost by adsorption on to mucus to a considerably greater extent than does phenol red, suggesting that chromic chloride is less satisfactory as a nonabsorbable gastric indicator.

Phenol red was introduced as a nonabsorbable indicator by Gorham (1923) and has since been used to study gastric emptying by a double sampling technique (George, 1968). Trivalent chromic salts were shown to be poorly absorbed in man (Donaldson and Barreras, 1966), and radioactive chromic chloride $\left({ }^{51} \mathrm{CrCl}_{3}\right)$ was recommended by Bloom, Jacobson, and Grossman (1967) and by Ivey and Schedl (1970) as a reliable gastric indicator; it has since been used in studies of gastric emptying by McKelvey (1970).

The reliability of ${ }^{51} \mathrm{CrCl}_{3}$ was questioned during the course of an experiment conducted in our laboratory as part of a clinical trial of gastric emptying. It was found that when a mixture of phenol red and ${ }^{51} \mathrm{CrCl}_{3}$ was used the ${ }^{51} \mathrm{CrCl}_{3}$ estimations gave consistently higher gastric volumes than did phenol red, and that when the gastricmucus residue was analysed separately it contained a much higher proportion of ${ }^{51} \mathrm{CrCl}_{3}$ than phenol red. These findings suggested that ${ }^{51} \mathrm{CrCl}_{3}$ might be adsorbed on to gastric mucus, and the present study was designed to make a quantitative assessment of the comparative losses of ${ }^{51} \mathrm{CrCl}_{3}$ and phenol red into the mucus fraction of gastric secretion.

\section{Materials and Methods}

\section{TEST TECHNIQUE}

Seven healthy student volunteers (A to $G$ ) and one postoperative hernia patient $(\mathrm{H})$, aged between 18 and 23, took part in the study. All were starved overnight and a nasogastric tube was positioned under $x$-ray control just proximal to the antrum. The gastric contents were aspirated, and if the aspirate was not clear the stomach was washed out

Received for publication 2 March 1971. with water. All the volunteers were given approximately $550 \mathrm{ml}$ of a test meal containing a mixture of phenol red and ${ }^{51} \mathrm{CrCl}_{3}, 20 \mathrm{ml}$ of which had first been taken as a control. The test solution was drunk as rapidly as possible, the drinking time always being less than five minutes. Gastric samples of 20 $\mathrm{ml}$ were withdrawn five minutes after drinking and then every 15 or 20 minutes. Ten $\mathrm{ml}$ was first withdrawn and discarded to eliminate contamination from the tube dead space. This was continued until the stomach had emptied.

PREPARATION OF TEST MEAL

A solution of $550 \mathrm{ppm}$ of phenol red is made up by dissolving $1 \mathrm{~g}$ of phenol red in $10 \mathrm{ml} \mathrm{N} \mathrm{NaOH}$ in a 2 litre volumetric flask (as modified by Hunt, 1954). This is made up to nearly 2 litres with distilled water and the $p \mathrm{H}$ is adjusted between 3 and 4 with $5 \mathrm{~N} \mathrm{HCl}$, before adding distilled water to the 2 litre mark.

The ${ }^{51} \mathrm{CrCl}_{3}$ initially contains $1 \mathrm{mCi}$ in $1 \mathrm{ml}$; this is dissolved in $200 \mathrm{ml}$ of the phenol red solution for ease of dispensing. Two hundred $\mu \mathrm{Ci}$ of this solution (the actual volume has to take into account the 27.8 days half-life of ${ }^{51} \mathrm{Cr}$ ) is then added to a 1 litre volumetric flask, and the volume made up to 1 litre with the phenol red solution to give a stock solution of $500 \mathrm{ppm}$ phenol red and $200 \mu \mathrm{Ci}$ per litre ${ }^{51} \mathrm{CrCl}_{3}$. The acidification of phenol red solution was to prevent ${ }^{51} \mathrm{CrCl}_{3}$ being precipitated out as insoluble oxide, as suggested by Bloom and colleagues (1967). The test solutions for subjects (A, B, C, D, E, F, and H) were made up by adding $50 \mathrm{ml}$ of the concentrated stock solution of phenol red and ${ }^{51} \mathrm{CrCl}_{3}$ to a $500 \mathrm{ml}$ bottle of $10 \%$ dextrose. The $10 \%$ dextrose solution was chosen as this was used in the original studies on gastric emptying referred to above. As it is a hypertonic solution it 
has a retarding effect on gastric emptying and more nearly reproduces the emptying conditions of a normal meal than does saline solution. In order to check that the $10 \%$ dextrose did not influence the adsorption of the indicators on to mucus the test meal for one subject $(G)$ was made up in distilled water.

As Bloom and colleagues (1967) suggested that a low $p \mathrm{H}$ was important for ${ }^{51} \mathrm{CrCl}_{3}$ recovery, the $p \mathrm{H}$ of the test solutions for $\mathrm{G}$ and $\mathrm{H}$ were altered and both solutions were adjusted to $p \mathrm{H} 1.4$ with $5 \mathrm{~N} \mathrm{HCl}$. To verify that the gastric samples from $G$ and $H$ remained acid, all samples were separately tested with narrow range low $p \mathrm{H}$ paper, and each $p \mathrm{H}$ was less than 2 apart from two samples from $\mathrm{H}$ which were $2 \cdot 25$ and $2 \cdot 75$.

The specific activity of the ${ }^{51} \mathrm{CrCl}_{3}$ was initially $167 \mathrm{mCi} / \mathrm{mg}$ as dispatched from the Radiochemicals Centre, Amersham, but allowing for decay was approximately $60 \mathrm{mCi} / \mathrm{mg}$ at the time of these experiments. This is similar to the specific activity of ${ }^{51} \mathrm{CrCl}_{3}$ as used by Ivey and Schedl (1970).

\section{ANALYSIS}

All samples were centrifuged to give a clear supernatant solution. Four $\mathrm{ml}$ from these supernatant solutions and $4 \mathrm{ml}$ from the control samples were pipetted into labelled $100 \mathrm{ml}$ volumetric flasks for phenol red analysis, and $4 \mathrm{ml}$ of the supernatant solutions and controls into labelled tubes for ${ }^{51} \mathrm{Cr}$ counting. Those samples with appreciable amounts of mucus were then selected, and the supernatant fluid was decanted off. If it was not possible to decant this fluid without disturbing the mucus, the mucus was washed gently once or twice with distilled water to remove as much as possible of the supernatant. The mucus samples were then made up to $10 \mathrm{ml}$ with distilled water and were microhomogenized in a Potter-Elvheim glass homogenizer. Four $\mathrm{ml}$ of the microhomogenized mucus was then pipetted into labelled $100 \mathrm{ml}$ volumetric flasks for phenol red analysis and $4 \mathrm{ml}$ into labelled tubes for ${ }^{51} \mathrm{Cr}$ counting.

To estimate phenol red a buffer solution was made by dissolving $27.5 \mathrm{~g}$ trisodium orthophosphate $\left(\mathrm{Na}_{3} \mathrm{PO}_{4} 12 \mathrm{H}_{2} \mathrm{O}\right)$ in 1 litre of water. Twenty $\mathrm{ml}$ of buffer was added to the labelled volumetric flasks and the volume made up to $100 \mathrm{ml}$ with distilled water. The purple colour is measured on a spectrophotometer at $560 \mathrm{~m} \mu$ using a $1 \mathrm{~cm}$ cell. The phenol red result for each sample is expressed as spectrophotometer reading of sample over spectrophotometer reading of control.

To count ${ }^{51} \mathrm{Cr}$ an additional counting tube with $4 \mathrm{ml}$ distilled water was used to estimate background radioactivity. The tubes were counted on a Nuclear
Chicago gamma counter using 5 cycled counts of 1,000 counts. Cycled counts were used to minimize the effects of any possible 'drift' in the counting conditions. The ${ }^{51} \mathrm{Cr}$ result for each sample is expressed as counts per minute of sample (less background) over counts per minute control (less background) For all supernatant and mucus samples a ratio of ${ }^{51} \mathrm{Cr}$ to phenol red is calculated.

\section{Validity of Study}

Any dilution of the indicator by gastric secretion or swallowed saliva and any loss of indicator by gastric emptying should apply equally to both indicators, and should not affect the final ratio of ${ }^{51} \mathrm{Cr}$ to phenol red for each sample, which should theoretically be 1 . The only factors that can affect the ratio is differing absorption or adsorption of one indicator relative to the other. The exact amount of phenol red or ${ }^{51} \mathrm{CrCl}_{3}$ in the initial solution is immaterial, provided the concentrations are sufficient for accurate estimation, as all samples are compared against the initial control. The volumes of mucus and amount of distilled water for homogenization varied in each mucus specimen, but the effect on both the phenol red/control result and the ${ }^{51} \mathrm{Cr} /$ control result should be identical, so that this error will cancel itself out in the final ${ }^{51} \mathrm{Cr} / \mathrm{phenol}$ red ratio, which should again theoretically be 1 if both indicators were equally adsorbed onto mucus.

\section{Results}

There were 34 samples of supernatant fluid, and 12 samples of mucus analysed for A, B, C, D, E, and F. There was at least one sample of mucus obtained from each subject. All but two of the ${ }^{51} \mathrm{Cr} / \mathrm{phenol}$ red ratios were less than 1 for the supernatant fluid samples, average $0.8113 \quad(\mathrm{P}<0.0005)$, indicating some loss of ${ }^{51} \mathrm{CrCl}_{3}$ relative to phenol red (Table I),

\begin{tabular}{|c|c|c|c|c|c|c|}
\hline \multirow{2}{*}{$\begin{array}{l}\text { Time of } \\
\text { Sample } \\
(\text { min })\end{array}$} & \multicolumn{6}{|c|}{ Subject } \\
\hline & $A$ & $\boldsymbol{B}$ & $C$ & D & $E$ & $F$ \\
\hline \multicolumn{7}{|c|}{ Supernatant } \\
\hline $\begin{array}{l}5 \\
25 \\
45 \\
65 \\
85 \\
105\end{array}$ & $\begin{array}{l}0752 \\
0.614 \\
0.561 \\
0.962 \\
0.717 \\
-\end{array}$ & $\begin{array}{l}0851 \\
0.897 \\
0.865 \\
0.842 \\
0.736 \\
0.769\end{array}$ & $\begin{array}{l}0.969 \\
0.704 \\
0.799 \\
0.860 \\
0754 \\
-\quad\end{array}$ & $\begin{array}{l}0.858 \\
0.873 \\
0.890 \\
0.778 \\
1.114 \\
0.818\end{array}$ & $\begin{array}{l}0.834 \\
0.801 \\
0.745 \\
0.785 \\
0.776 \\
0.965\end{array}$ & $\begin{array}{l}0.837 \\
0.713 \\
0.724 \\
0.674 \\
1.052 \\
0.770\end{array}$ \\
\hline $\begin{array}{l}\text { Mucus } \\
45 \\
65 \\
85 \\
105\end{array}$ & $\begin{array}{l}- \\
6 \cdot 520 \\
6 \cdot 180 \\
-\end{array}$ & $\begin{array}{l}\bar{Z} \\
\overline{15} \cdot 000\end{array}$ & $\overline{\overline{9}}$ & $\begin{array}{l}\overline{-} \\
13.980 \\
5.360\end{array}$ & $\begin{array}{l}\frac{11 \cdot 210}{2} \\
9 \cdot 330\end{array}$ & $\begin{array}{r}3.250 \\
2.700 \\
16.730 \\
11.500\end{array}$ \\
\hline
\end{tabular}

Table I Ratio of ${ }^{51} \mathrm{Cr}$ to phenol red in supernatant and mucus in six subjects 


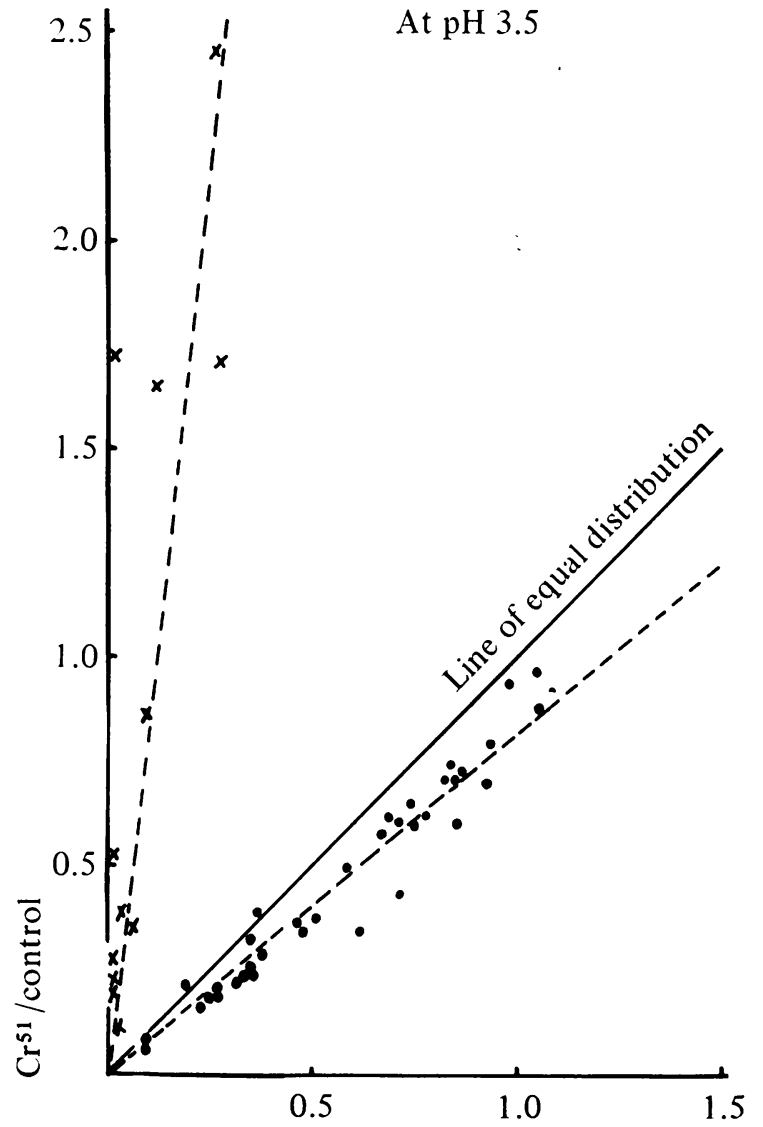

Phenol red/control

FIG. 1 Ratio of ${ }^{51} \mathrm{Cr}$ to phenol red at $\mathrm{pH} 3.5$ (six subjects) x mucus samples; supernatant samples.

and all the ${ }^{51} \mathrm{Cr} / \mathrm{phenol}$ red ratios for the mucus samples were greater than 1 , average 8.461 $(\mathrm{P}<0.0005)$ suggesting that ${ }^{51} \mathrm{CrCl}_{3}$ is adsorbed onto the gastric mucus (Table I). The actual results for each sample of phenol red and ${ }^{51} \mathrm{CrCl}_{3}$ relative to controls can be compared diagrammatically (see Fig. 1) where, assuming equal distribution of both substances, a perfect correlation should fall along a line drawn at $45^{\circ}$ to both axes. As can be seen, all the supernatant fluid readings fall towards the phenol red axis and all the mucus samples fall towards the ${ }^{51} \mathrm{CrCl}_{3}$ axis.

All but one of the ${ }^{51} \mathrm{Cr} / \mathrm{phenol}$ red ratios for the 13 supernatant fluid samples in $G$ and $H$ were less than 1 , average $0.9326(P=0.01)$ (Table II), and all the ${ }^{51} \mathrm{Cr} /$ phenol red ratios for the seven mucus samples were greater than 1 , average $3.940(P=0.01)$

\begin{tabular}{lll}
\hline Time of Sample (min) & \multicolumn{2}{l}{ Subject } \\
\cline { 2 - 3 } & $\boldsymbol{G}$ & $\boldsymbol{H}$ \\
\hline Supernatant & 0.972 & 0.979 \\
5 & 0.882 & 1.008 \\
20 & 0.946 & 0.967 \\
35 & 0.876 & 0.958 \\
50 & 0.654 & 0.850 \\
65 & 0.649 & 0.684 \\
80 & - & 0.924 \\
95 & & \\
Mucus & 2.197 & 31.040 \\
50 & 15.320 & 2.250 \\
65 & 10.310 & 4.600 \\
80 & - & 17.230 \\
90 & & \\
\hline
\end{tabular}

Table II Ratio of ${ }^{51} \mathrm{Cr}$ and phenol red in supernatant and mucus in two subjects

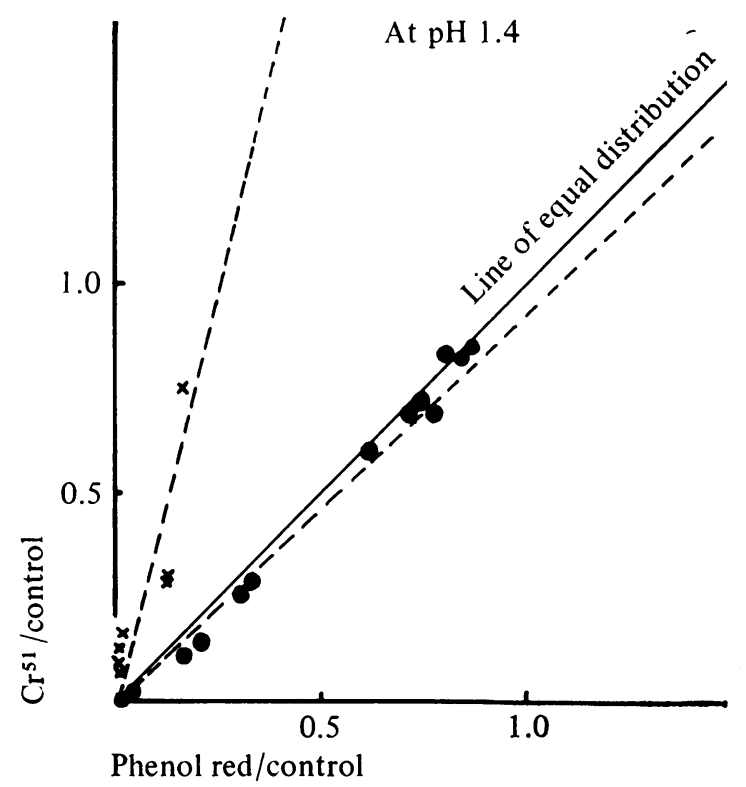

FIG. 2. Ratio of ${ }^{51} \mathrm{Cr}$ to phenol red at $\mathrm{pH} 1.4$ (two subjects) $\mathrm{x}$ mucus samples; - supernatant samples.

(Table II). These results can also be compared diagrammatically (Fig. 2).

\section{Discussion}

Donaldson and Barreras (1966) concluded that ${ }^{51} \mathrm{CrCl}_{3}$ was a good nonabsorbable indicator for studies of intestinal absorption and excretion, on the basis that virtually all the ingested ${ }^{51} \mathrm{CrCl}_{3}$ could be recovered in the faeces. Bloom and colleagues (1967) compared various substances for use as gastric dilution indicators, including ${ }^{51} \mathrm{CrCl}_{3}$ and 
phenol red. They found that there was a 5-8\% loss of phenol red from the Heidenhain pouch in the dog (less if the stomach was actively secreting), but found that ${ }^{51} \mathrm{CrCl}_{3}$ could be recovered almost $100 \%$ when the stomach was highly acidic. Recovery was not satisfactory at neutral solutions possibly due to precipitation of chromic oxide. Schanker, Shore, Brodie, and Hogben (1957) found, however, a $98 \%$ recovery rate of phenol red from the rat stomach.

Ivey and Schedl (1970), in a search for gastric nonabsorbable indicators for study in man, compared the absorption of ${ }^{51} \mathrm{CrCl}_{3}$, phenol red, and polyethylene glycol by the human stomach at $p \mathrm{H} 1$. They stated in their summary that there was minimal absorption from the stomach of all three indicators, and that all were equally valid. They did state, however, that for the ${ }^{51} \mathrm{Cr} / \mathrm{ph}$ enol red ratios, charted as in Fig. 1, slightly more points lie towards the phenol red axis, and in their discussion they state that there was less complete recovery of an indicator on first instillation into the stomach, possibly due to adsorption to gastric surface or contents, and this was found for all indicators. Since then ${ }^{51} \mathrm{CrCl}_{3}$ has been used as a means of studying gastric emptying by McKelvey (1970) using a balanced meal containing protein, fat, and carbohydrate at $p \mathrm{H} \mathrm{6.3.}$ This study does not measure absolute gastric absorption rates for phenol red and ${ }^{51} \mathrm{CrCl}_{3}$ as this can only be done by total indicator recovery studies in animals with gastric pouches. However, indicator recovery from animals with gastric pouches may well not reflect what happens in the intact stomach of man.

From this present study it is felt that ${ }^{51} \mathrm{CrCl}_{3}$ appears to be bound in some way to gastric mucus, although the actual amount may not be very great. This tendency was lessened but not preventable by a low $p \mathrm{H}$ (as Bloom et al suggest) as both subjects $\mathrm{G}$ and $\mathrm{H}$ had a high ${ }^{51} \mathrm{Cr} / \mathrm{phenol}$ red ratio in the mucus. There was little difference between the results in $G$ and $H$ and so it seems unlikely that $10 \%$ dextrose has any effect on the distribution of these indicators in the stomach. These results agree with other observations (R. J. Clarke, unpublished data) from counting mucus in gastric emptying studies in duodenal ulcer patients when a ${ }^{51} \mathrm{Cr} /$ phenol red ratio in the mucus of about $9: 1$ has been found. Even if a $p \mathrm{H}$ of 1 helps to prevent ${ }^{51} \mathrm{CrCl}_{3}$ adsorption, there are practical difficulties keeping such a low $p \mathrm{H}$ in emptying studies, and both subjects $\mathrm{G}$ and $\mathrm{H}$ complained bitterly of the unpleasant vinegar taste after drinking the solutions at $p \mathrm{H} \mathrm{1.4}$. It is therefore suggested that ${ }^{51} \mathrm{CrCl}_{3}$ is not an entirely suitable indicator for gastric emptying studies.

We should like to acknowledge support from the Medical Endowment Research Fund of the United Birmingham Hospitals (R. J. C.) and from the Medical Research Council (J. A. W.).

Please send requests for reprints to J. A.W.

\section{References}

Bloom, D. S., Jacobson, E. D., and Grossman, M. I. (1967). Validation of dilution indicators in the stomach. Gastroenterology, 52, 205-210.

Donaldson, R. M.,Jr., and Barreras, R. F. (1966). Intestinal absorption of trace quantities of chromium. J. Lab. clin. Med., 68, 484-493.

George, J. D. (1968). New clinical method for measuring the rate of gastric emptying: the double sampling test meal. Gut, 9, 237-242.

Gorham, F. D. (1923). The factor of dilution in gastric analysis. J. Amer. med. Ass., 81, 1735-1742.

Hunt, J. N. (1954). The inhibitory action of sucrose on gastric digestive activity in patients with peptic ulcers. Guy's Hosp. Rep. 103, 161-173.

Ivey, K. J., and Schedl, H. P. (1970). Gastric nonabsorbable indicators for studies in man. Gastroenterology, 59, 234-239.

McKelvey, S. T. D. (1970). Gastric incontinence and post-vagotomy diarrhoea. Brit. J. Surg., 57, 741-747.

Schanker, L. S., Shore, P. A., Brodie, B. B., and Hogben, C. A. M. (1957). Absorption of drugs from the stomach. I. The rat. J. Pharmacol. exp. Ther., 120, 528-539. 